\title{
Por que se Importar com a Desigualdade*
}

\author{
Celia Lessa Kerstenetzky
}

\begin{abstract}
s crescentes desigualdades socioeconômicas das duas últimas A décadas têm despertado intenso interesse acadêmico e não acadêmico, como atestam as prolixas literaturas universitária, de organismos internacionais oficiais e de organizações não-governamentais. Não obstante, à exceção da Europa Nórdica onde figuram com destaque na agenda pública, as desigualdades estão notavelmente ausentes como objeto explícito de políticas públicas nacionais, mesmo quando, como no caso europeu ocidental, essas políticas têm efeitos redistributivos.
\end{abstract}

Há uma série de razões para essa elipse. Em diversos países da Europa Ocidental, por exemplo, apesar de crescentes as desigualdades, o seu nível é ainda relativamente baixo, enquanto em países do continente africano, a insuficiência absoluta de recursos, mais do que sua dis-

\footnotetext{
* Versões parciais deste trabalho foram apresentadas no Rio Inequality Workshop, julho de 2001, e no $3^{\circ}$ Encontro da Associação Brasileira de Ciência Política - ABCP, julho de 2002, beneficiando-se dos comentários de Fábio Wanderley Reis e Isabel Ribeiro, e, posteriormente, das observações feitas por Joshua Cohen, quando de minha estada como visiting scholar no Departamento de Ciência Política do MIT, Jaques Kerstenetzky, Elisa Reis, Marcos Lisboa e Octavio Amorim Neto. A todos agradeço e isento de responsabilidade pelo resultado final. Sou grata, ainda, ao CNPq por bolsas de produtividade de pesquisa e de pós-doutoramento concedidas.
}

DADOS - Revista de Ciências Sociais, Rio de Janeiro, Vol. 45, nㄴ 4, 2002, pp. 649 a 675. 
tribuição, é certamente o problema mais agudo. Além disso, uma tendência que envolve a grande maioria dos países, independentemente de sua renda per capita, regime político e políticas públicas específicas, pode bem ter sua origem em eventos que ocorrem em escala global, e requerer reparação a este nível, como a crise da dívida dos anos 80 (Galbraith, 2002) e o movimento especulativo de capitais que a ela se seguiu, com os subseqüentes efeitos perversos sobre a distribuição interna de riqueza e renda. Em outras palavras, inexperiência, urgência e globalização financeira fariam com que políticas públicas explicitamente orientadas para a redução das desigualdades parecessem singularmente não atraentes.

Contudo, razões respeitáveis escasseiam quando se trata de países com níveis de desigualdade persistentemente elevados. Este é o caso da maioria dos países latino-americanos e, em particular, do Brasil, que não apenas ostenta, possivelmente, a pior distribuição de renda do mundo como tem uma dispersão de renda próxima à que existe no mundo ${ }^{1}$; mas também dos EUA, que se destacam a esse respeito entre os países desenvolvidos pelo menos há duas décadas. Aqui, ocorrem-me duas razões de respeitabilidade duvidosa para a referida elipse, muito embora proferidas na intimidade dos pequenos círculos nem por isso desprovidas de poder de fogo: 1) a convicção de que enfrentar a desigualdade não é politicamente realista;2) a crença de que falido o socialismo as we know it, não há horizonte normativo que seja ao mesmo tempo respeitável e factível. Em conjunto, estas duas razões recomendariam o deslocamento do foco do interesse público para os problemas mais urgentes de exclusão social e pobreza extrema, e para o apoio a políticas sociais orientadas para o seu alívio. A desigualdade existiria, como negar?, mas essencialmente não contaria.

Neste ensaio, pretendo inventariar e examinar argumentos e evidências disponíveis na literatura especializada contemporânea que desacreditam as duas suposições acima. Estes essencialmente indicam que, se, de um lado, mesmo o alcance sustentável de objetivos "mais realistas", como o combate à pobreza extrema, pode requerer a promoção da desigualdade para o primeiro plano da agenda pública, de outro, há à disposição dos interessados um elenco de opções sérias, como atestam algumas perspectivas igualistaristas pós-rawlsianas. 
A estrutura do texto é a seguinte. Na seção 1, justifico a abordagem e apresento um resumo dos argumentos. Nas seções 2 e 3 , onde reporto com brevidade resultados encontrados na literatura, apresento as conseqüências previsíveis das desigualdades extremas sobre os objetivos consensuais do cenário "politicamente realista". Na seção 4, que lida essencialmente com as opções normativas e onde se concentra o maior esforço interpretativo deste ensaio, discuto as desigualdades como resultados previsíveis e imprevisíveis de instituições, respectivamente, injustas e justas. A seção 5 conclui com os comentários finais.

\section{PRELIMINARES}

Realismo Político - Designarei como "politicamente realista", no contexto do problema da desigualdade, um conjunto específico de objetivos passíveis de apoio generalizado, no sentido mínimo de o seu endosso, por parte de indivíduos e grupos, ser independente da posição destes na distribuição de renda, e, em particular, não requerer dos mesmos um ethos igualitarista. Esse conjunto incluiria os seguintes objetivos: redução da pobreza, crescimento econômico, coesão social e democracia. A sugestão é que, na medida em que essas finalidades razoavelmente consensuais são bloqueadas quando ocorrem níveis elevados de desigualdade econômica, o apoio a políticas públicas orientadas para a redução das desigualdades é mais provável. Portanto, o primeiro passo é examinar as relações causais entre desigualdade econômica extrema e déficit na realização de objetivos não distributivos. Exame da literatura indica que, de fato, a desigualdade nesse caso importa e muito, e importa por suas conseqüências sobre coisas que importam intrinsecamente.

Note, entretanto, que meu argumento é conseqüencialista, mas não se restringe a assinalar efeitos para o bem-estar ou vantagens diretas para indivíduos e grupos. Portanto, não é o mesmo que apelar ao interesse próprio de indivíduos e grupos, para ganhar a adesão deles a políticas redistributivas, por conta dos efeitos esperados sobre o seu bem-estar direto. Esses argumentos, a meu ver, enfrentam dois problemas: uma definição ultralimitada de interesse próprio (excluindo, por exemplo, do conjunto de preferências dos indivíduos interesses outros que não sua vantagem direta $)^{2}$ e a postulação de inexistência de informação incompleta e de problemas cognitivos de natureza diversa na percepção dos "verdadeiros" interesses dos atores sociais (que tomaria, por exemplo, como auto-evidente o apoio dos menos 
favorecidos a políticas redistributivas) ${ }^{3}$. Meu argumento "igualitarista" conseqüencialista, alternativamente, depende das seguintes suposições: suspendendo juízo com relação ao conteúdo das preferências dos indivíduos, supõe que o possível apoio àqueles objetivos gerais seja relativamente independente da posição do indivíduo na estrutura de distribuição; supõe ainda que o conhecimento de possíveis nexos causais no mundo social afete tanto as crenças das pessoas quanto suas preferências. Conclui que preferências não igualitaristas podem conduzir a uma escolha social relativamente igualitarista, uma vez esclarecidos os nexos conectando a satisfação daquelas preferências a políticas redistributivas. Portanto, a atribuição de irrealismo político à expectativa de apoio amplo (i.e., não condicionado pela posição do indivíduo na estrutura de distribuição) a políticas redistributivas depende de supostos mais heróicos do que os que adoto aqui, em particular, que os indivíduos agem exclusivamente segundo o imperativo de vantagens diretas para si, e que suas escolhas são instantaneamente bem informadas.

Horizonte Normativo - Quanto à suposição relativa à inexistência de opções normativas respeitáveis e factíveis, o ensaio avalia a alternativa contemporânea mais completa disponível, a teoria rawlsiana de justiça, a partir de sua potencialidade para minimizar as desigualdades. Conclui que esta teoria apresenta, do ponto de vista da questão da desigualdade, problemas não fatais, para a solução dos quais as ciências sociais, em seu presente estado, tem muito a contribuir. Segundo essa teoria, as desigualdades importam se e somente se elas são injustas. Desigualdades justas são aquelas que, resultando da distribuição igual de liberdades e oportunidades (justas), promovem a melhoria da situação dos menos favorecidos (Kerstenetzky, 1999). Aqui há dois problemas que eu gostaria de mencionar. Por um lado, a teoria rawlsiana repousa em preferências mais estritas que as postuladas no cenário "politicamente realista", na medida em que supõe que a articulação de nosso senso de justiça resultaria em uma ordenação única de preferências e valores que, por sua vez, do ponto de vista da distribuição de renda e riqueza, indicaria prioridade para a situação dos menos favorecidos. Presume, por assim dizer, um ethos "igualitarista-prioritarista". O resultado é uma combinação de igualdade de oportunidades com monitoramento de resultados (tendo em vista que um subconjunto dos resultados possíveis é excluído, qual seja, o conjunto de distribuições onde as vantagens para os mais favorecidos 
vêm desacompanhadas de vantagens para os menos favorecidos). Essa dificuldade pode ser mitigada desde que a prioridade aos menos favorecidos seja compreendida como uma instância do (menos viesado distributivamente) princípio da eficiência, como proponho na seção 4.

Por outro lado, essa teoria gera uma certa indeterminação com relação aos níveis de desigualdade toleráveis, revelando-se permissiva a qualquer distribuição que resulte daquela prioridade - o que ensejou intenso debate em torno à sua sensibilidade à demanda por incentivos por parte dos mais ricos, como contrapartida à contribuição destes à melhoria da situação dos mais pobres (G. A. Cohen, 1992; 1995; 1997; Williams, 1998; Estlung, 1998; Pogge, 2000; J. Cohen, 2002). Ela aprovaria, por exemplo, a atual dispersão de renda e riqueza vigente no Brasil, uma vez que, ainda que muito discretamente, a situação dos menos favorecidos teria melhorado nas últimas décadas, contra um pano de fundo de expansão generalizada de direitos e oportunidades (Quadro 1). Essa indeterminação, por sua vez, pode trazer problemas em termos da efetivação dos objetivos consensuais do cenário "politicamente realista" - redução significativa da pobreza, retomada do crescimento econômico, coesão social, consolidação da democracia -, que retém prioridade também na justiça rawlsiana.

Quadro 1

Brasil: Ganhadores e Perdedores por Décimos da Distribuição (1981/1995)

\begin{tabular}{|l|c|c|c|c|}
\hline \multirow{2}{*}{} & \multicolumn{2}{|c|}{$1990 / 95$} & \multicolumn{2}{c|}{$1981 / 95$} \\
\cline { 2 - 5 } & $\mathrm{G}$ & $\mathrm{P}$ & $\mathrm{G}$ & $\mathrm{P}$ \\
\hline Em termos absolutos & $1-10$ & - & $1-10$ & - \\
Em termos relativos & $1-7$ & $8-10$ & 10 & $1-9$ \\
Ambos & $1-7$ & - & 10 & - \\
\hline
\end{tabular}

Fonte: Ferreira e Litchfield (2000:58).

Ora, se a persistência de altos níveis de desigualdade econômica em uma sociedade "corrigida" por instituições rawlsianas pode estar associada à demanda por incentivos por parte dos mais ricos, já que nela, grosso modo, não se restringe o domínio das preferências dos indivíduos (interpretação privilegiada por G. A. Cohen), pode também resultar de conseqüências não pretendidas das instituições desenhadas para justificá-la ou mesmo minorá-la. A primeira hipótese, da demanda por incentivos, sublinha a necessidade de um ethos igualitaris- 
ta, para se alcançar justiça igualitária, como requisito complementar ou talvez alternativo ao desenho de instituições igualitaristas de justiça. Pode-se adiantar, contudo, que sem uma teoria aqui, uma "ethologia", a postulação desse ethos tanto "resolve" a justiça igualitária quanto sua ausência a torna inconcebível. Por este motivo, favorecerei (cf. seção 4) a segunda hipótese, a de que possivelmente a economia das desigualdades rawlsianas seja inadequada, e os efeitos de composição não estejam sendo devidamente considerados.

Se este for o caso, a sugestão (apenas) encaminhada neste trabalho é que os igualitaristas têm pelo menos duas opções aqui: permanecendo rawlsianos (isto é, excluindo a alternativa de engenharia do ethos e concentrando-se no papel das instituições da chamada "estrutura básica" da sociedade), devem observar os impactos das desigualdades residuais sobre os objetivos consensuais, para resolverem a indeterminação de sua teoria - e, portanto, calibrarem as desigualdades residuais tendo em vista o dano que podem causar aos objetivos consensuais. Ou então, moverem-se francamente para alternativas mais atentas à sensibilidade das desigualdades a resultados não pretendidos da ação de instituições justas, como parece ser a proposta de instituição de uma renda básica incondicional, a maior possível, de Phillipe van Parijs (1995; 2001).

A ironia é que as conseqüências também importam quando a desigualdade importa intrinsecamente: na calibragem da desigualdade bem como na escolha do estilo de igualitarismo. De qualquer modo, essa situação tem como efeito o reconhecimento dos limites dos princípios normativos e da importância, raramente reconhecida, das teorias sociais, políticas e econômicas, que constituem os supostos factuais daqueles princípios. Essa interação entre teoria social lato sensu e teoria normativa parece essencial para emprestar respeitabilidade e exeqüibilidade a princípios de justiça no debate sobre prioridades e políticas públicas. Passo, agora, ao detalhamento dos argumentos.

\section{DESIGUALDADE COMO CAUSA (I): POBREZA E CRESCIMENTO ECONÔMICO}

\section{Pobreza}

Durante um longo inverno, reinou entre os economistas a crença de que as desigualdades eram necessárias à eliminação da pobreza, em 
virtude de seus reconfortantes efeitos sobre o crescimento da riqueza. A história é simples: as desigualdades de remuneração pela utilização dos diferentes recursos econômicos funcionariam como incentivo ao esforço produtivo, levando, na ausência de imperfeições e incompletudes do mercado, ao crescimento. Cedo ou tarde os efeitos do crescimento econômico se fariam sentir em todas as camadas sociais, chegando aos mais pobres especialmente pela geração de emprego e renda decorrente do uso produtivo dos recursos econômicos (Smith, 1983; Kerstenetzky, 2000). No entanto, a evidência de processos de crescimento econômico, e mesmo de crescimento acelerado, que não eliminaram a pobreza, provocou uma importante onda revisionista na literatura econômica, qualificando o automatismo suposto nas relações entre crescimento e eliminação da pobreza.

O caso do Brasil é particularmente notável. Como é bem conhecido, especialmente a partir da ampla divulgação entre nós dos resultados da pesquisa empírica de Ricardo Paes de Barros, algo em torno de 1/3 dos brasileiros é pobre, muito embora o país seja relativamente rico quando sua renda per capita é colocada em perspectiva internacional e tenha passado por fases relativamente recentes de crescimento acelerado (Barros et alii, 2000a). Na verdade, a crer-se nos mesmos resultados, o patamar de pobreza revelou-se pouco sensível ao crescimento econômico em duas décadas. Em particular, uma das simulações revela que, mantida a distribuição de renda, a eliminação da pobreza requereria cerca de três décadas de crescimento contínuo anual de 5\% de nossa renda per capita.

A explicação para a persistência da pobreza em um país relativamente rico, de novo, parece simples: grosso modo, a renda das pessoas deriva da utilização dos ativos que possuem. Como no Brasil a propriedade de ativos valiosos - capital físico, terra, educação, ativos financeiros - é, historicamente, muito concentrada, seguem-se os persistentemente baixos níveis de renda dos mais pobres. (A evidência empírica para o caso da educação - "capital humano" - é significativa, sobretudo quando se considera a desigualdade salarial (idem).) O pobre brasileiro, como o americano, aliás, trabalha - "é digno", deserving -, mas, em função de sua destituição dos ativos que têm valor, ganha miseravelmente pouco: ele integra o contingente de trabalhadores "informais" que hoje responde por cerca de metade de todo o mercado de trabalho no país. Ademais, sua capacidade de endividamentode oferecer colateral por exemplo-, para financiar o acesso aos ativos 
valiosos que poderiam libertá-lo de sua pobreza, é nula. Não parece haver outro meio de prover acesso a esses ativos senão promover algum tipo de política redistributiva: educação pública, crédito subsidiado, saúde pública, reforma agrária etc.

\section{Crescimento Econômico}

O reconhecimento de que a pobreza pode decorrer da desigualdade extrema de riqueza (posse dos ativos valiosos) não questiona diretamente a microeconomia dos incentivos, essencial à visão de que desigualdades são cruciais para o crescimento econômico. Poderia acontecer a situação em que a redistribuição de riqueza financiada através de taxação sobre salários e lucros produzisse desincentivos ao trabalho e à poupança que ulteriormente afetassem, de modo negativo, $\mathrm{o}$ crescimento, piorando a situação de todos, pobres e ricos (Epstein, 2002; Hayek, 1993). Mas se as oportunidades de geração de renda - a posse de riqueza - se encontram tão mal distribuídas, pode bem ser o caso de as perdas econômicas incorridas pela taxação aos mais ricos serem mais do que compensadas pelos ganhos decorrentes da abertura de oportunidades aos menos favorecidos. De fato, esta é a aposta de um conjunto crescente de economistas que estão constituindo um novo cânone na teoria econômica nas últimas décadas (Aghion et alii, 1998; Benabou, 1996; Ferreira, 1999; 2000). Segundo eles, a desigualdade extrema de acesso a ativos valiosos, de oportunidades de geração de renda, traria danos importantes ao processo de crescimento econômico em virtude da utilização ineficiente dos recursos econômicos.

Segundo Philippe Aghion, por exemplo, os argumentos pró-concentração de riqueza, por conta de seus efeitos sobre a acumulação de capital, supõem, em geral, indivíduos idênticos e mercados de capitais perfeitos. Porém, as hipóteses mais relevantes de heterogeneidade dos indivíduos (sobretudo diferenças na dotação de capital humano) e imperfeições no mercado de capitais (cujo acesso, na prática, é diferenciado, dependente da riqueza) não garantiriam a ligação virtuosa entre concentração de riqueza e crescimento. Nesse cenário, e na vigência de retornos decrescentes, a concentração extrema de riqueza distorceria o acesso às oportunidades de modo perverso ao crescimento. Quando o crédito não está disponível, a redistribuição de riqueza em favor dos mais pobres, ou seja, os indivíduos com os retornos marginais mais altos ao investimento, promoverá crescimento (Aghion et 
alii, 1998:18). Além disso, a concentração extrema de riqueza não computaria os possíveis efeitos positivos sobre o crescimento associados à redução do risco moral, por conta da posse de riqueza por parte dos menos favorecidos (o que os incentivaria a aumentar seu esforço produtivo $)^{4}$. Em síntese, nesse cenário de indivíduos heterogêneos e crédito determinado pela riqueza, a desigualdade extrema de riqueza desvirtuaria não apenas o acesso a oportunidades promotoras de crescimento, como distorceria os incentivos ao esforço produtivo dos mais pobres, igualmente promotores de crescimento. Há dois recursos para os quais a evidência pró-distribuição por conta de seus efeitos sobre o crescimento parece decisiva: capital humano e terra.

Na literatura brasileira, alguns trabalhos empíricos avaliam o impacto de desigualdades de oportunidades educacionais (ver, p. ex., Barros et alii, 2000b) e desigualdade de acesso à terra sobre o crescimento econômico. No caso da terra, contrariando a tese de que a grande propriedade é necessariamente mais produtiva (o que de todo modo não exclui a hipótese de propriedade coletiva como as cooperativas agrícolas), e que, portanto, a reforma agrária é, quando muito, uma política social orientada para a correção de uma injustiça social, estudos recentes assinalam ganhos de produtividade associados à distribuição da terra em benefício da pequena e média agricultura familiar voltada para a produção de alimentos (Barros et alii, 2000c; Guanziroli, 1999). No âmbito de organismos internacionais como o Banco Mundial e o FMI, cresce a convicção quanto à necessidade de enfatizar processos de crescimento consistentes com o chamado pro-poor growth, essencialmente centrados na redistribuição de terra e no combate à pobreza rural (Birdsall e Londono, 1997).

Cabe observar ainda que a evidência empírica para a relação positiva entre desigualdade de renda e crescimento parece particularmente fraca em estimativas para sete democracias ricas em 1998. Ainda que nada seja definitivo a respeito de qualquer estatística, é interessante notar que a economia americana, a mais desigual e a mais rica (e também a que mais trabalha), não aparece, entretanto, como a mais eficiente (relação produto/hora trabalhada), sendo superada, neste particular, pelas mais igualitárias França e Alemanha. Neste caso, a diferença de produto parece estar relacionada a distintas preferências, de americanos e europeus, entre trabalho e lazer, ou entre consumo e lazer (Jencks, 2002) (Quadro 2). 
Quadro 2

Desigualdade Econômica, Produto, Esforço

e Eficiência em Sete Democracias Ricas

(1998)

\begin{tabular}{|l|c|c|c|c|c|c|c|}
\hline & EUA & $\begin{array}{c}\text { Reino } \\
\text { Unido }\end{array}$ & Austrália & Canadá & França & Alemanha & Suécia \\
\hline Razão 90/10* & 5,6 & 4,6 & 4,3 & 4,0 & 3,5 & 3,2 & 2,6 \\
\hline $\begin{array}{l}\text { PIB per capita } \\
\text { (US\$ 1998) }\end{array}$ & 32.184 & 21.673 & 24.192 & 25.179 & 21.132 & 23.010 & 21.799 \\
\hline $\begin{array}{l}\text { Esforço } \\
\text { \% pop. emp. } \\
\text { hrs/trabalhador }\end{array}$ & 48,6 & 45,9 & 45,8 & 46,6 & 38,1 & 43,5 & 45,1 \\
\hline $\begin{array}{l}\text { Eficiência } \\
\text { PIB/trab. }\end{array}$ & 60.106 & 44.280 & 45.558 & 49.007 & 55.714 & 50.616 & 44.000 \\
PIB/hora & 32,25 & 25,58 & 25,57 & 27,55 & 35,55 & 33,52 & 27,01 \\
\hline
\end{tabular}

Fonte: Jencks (2002).

(*) Razão entre as rendas médias familiares do 9ํㅜ decil e do $1^{\circ}$ decil da distribuição.

Finalmente, além de não necessárias ao crescimento e provavelmente prejudiciais a ele quando extremas, as desigualdades parecem resistir igualmente a outro mito da teoria econômica: de que com o progresso econômico elas tenderiam a diminuir depois de terem sido funcionais em uma etapa inicial. A assim chamada hipótese de Kuznets cederia diante da evidência das últimas décadas (Deininger e Squire, 1998; Aghion et alii, 1998; Ferreira, 1999). Também em países desenvolvidos, as desigualdades de renda estão crescendo; elas não tendem a cair automaticamente com o desenvolvimento, e, de fato, sem a intervenção do Estado de Bem-Estar teriam sido bem maiores (Quadro 3).

Em resumo, desigualdade extrema de riqueza gera pobreza e crescimento deficiente, e a eficiência econômica não está, de modo inequívoco, positivamente associada à desigualdade de renda. Além disso, as desigualdades de renda não tendem a desaparecer automaticamente no horizonte do longo prazo econômico.

\section{DESIGUALDADE COMO CAUSA (II): COESÃO SOCIAL E DEMOCRACIA}

\section{Coesão Social}

Esta seção discute o conflito, senão real ao menos potencial, entre dois fenômenos modernos: de um lado, a crença na igualdade moral entre 
Quadro 3

Variação (Arredondada) do Índice de Pobreza* e da Desigualdade (Gini) em Democracias Desenvolvidas, antes e depois das Transferências

(1981/1995)

\begin{tabular}{|l|c|c|c|c|}
\hline & Pobreza & Desigualdade & $\begin{array}{c}\text { Pobreza antes das } \\
\text { Transferências de } \\
\text { Renda }\end{array}$ & $\begin{array}{c}\text { Desigualdade antes das } \\
\text { Transferências de } \\
\text { Renda }\end{array}$ \\
\hline Inglaterra & +5 & +7 & +13 & +11 \\
Canadá & -1 & -3 & +6 & +3 \\
EUA & $+2,5$ & +4 & +5 & +3 \\
Holanda & +3 & 0 & +2 & -2 \\
França & +0 & 0 & +8 & +5 \\
Alemanha & +3 & +1 & +6 & -2 \\
Noruega & +0 & 0 & +6 & +4 \\
Suécia & -0 & +2 & +9 & +2 \\
Finlândia & -3 & 0 & +11 & +11 \\
\hline
\end{tabular}

Fonte: Neubourg (2002).

(*) Percentual da população com renda inferior a 50\% da renda mediana.

os indivíduos e os efeitos desta sobre as expectativas desses indivíduos de alcançar certos objetivos na sociedade em que vivem; de outro, a realidade das desigualdades socioeconômicas na forma que Charles Tilly (1998) denomina "desigualdades duráveis". Trata-se de desigualdades que se repetem historicamente, entre grupos sociais, étnicos, de certas localidades, de gênero, de tal modo que ter nascido em um determinado grupo, local, etnia ou gênero revela-se o melhor preditor das chances de "sucesso" de um indivíduo dentro da sociedade, ou da quantidade de opções reais diante dele. Chame essas expectativas de "expectativas de posição". As expectativas que assim se formam são fixas, em contraste com as variáveis prometidas pela noção de igualdade moral, vale dizer, as "expectativas legítimas". A economia desse conflito não requer, creio, grande imaginação: pode resultar em conformismo, desespero, violência, suicídio social, e tantas formas de anomia, em outras palavras, "desperdício" de recursos sociais. A política desse conflito pode resultar tanto em sociedades segmentadas (Rae, 1999) quanto em conflito explícito e violência. A evidência americana, por exemplo, registra maiores índices de criminalidade nas metrópoles com maiores desigualdades econômicas (Jencks, 2002). 
Minimamente, pode-se afirmar que a coesão social é função inversa do conflito entre expectativas legítimas e expectativas de posição ${ }^{5}$. Em face de desigualdades resilientes e extremas, esse conflito pode ser minimizado de uma entre três maneiras: ou cedem as expectativas legítimas dos menos favorecidos de modificar sua situação (como parece ser o caso das democracias segmentadas), contaminadas por expectativas de posição que são reforçadas ao longo do tempo por efeito ou inoperância de instituições sociais; ou modificam as expectativas de posição em resposta a uma reformulação da regra de distribuição de oportunidades dentro da sociedade; ou, ainda, ambas se alteram. De todo modo, caso o ajuste seja feito sobre as expectativas legítimas, o "sucesso" do modelo de sociedade vai estar dependente do sucesso da segmentação: condomínios fechados, espaços privados, TVs a cabo etc.

\section{Democracia}

Parte das expectativas de igualdade moral poderia ser satisfeita pelos sistemas legal e político, por intermédio do reconhecimento de direitos civis e políticos iguais, como consubstanciado no regime democrático. Interessa, nesse contexto, saber em que medida a igualdade de direitos civis e políticos é afetada por desigualdades socioeconômicas. Aparentemente, a associação é tão óbvia que cientistas políticos como Arend Lijphart tomam a desigualdade econômica como proxy da desigualdade política, "mais difícil de se observar diretamente" (1999:282), seguindo Robert Dahl em sua afirmação de que recursos econômicos podem ser convertidos em recursos políticos (1996:645). Estas observações podem ser traduzidas em uma fórmula tão trivial quanto pétrea: a efetividade da igualdade de direitos civis e políticos é perturbada pela desigualdade econômica.

Quanto aos direitos políticos, como observa O'Donnell (1999), seu exercício pleno, em uma democracia estabelecida, não se esgotaria no voto ou na elegibilidade, mas guardaria ainda relação com condições menos formais, tais como a capacidade dos indivíduos de expressarem opiniões, deliberarem, participarem de partidos políticos e de campanhas eleitorais. Sem negar a importância de outros fatores, notadamente motivacionais, essas capacidades são singularmente vulneráveis à disponibilidade de recursos, como informação, tempo e dinheiro, cuja distribuição, pois, importa uma vez que afeta a conversão de direitos políticos formais em direitos políticos efetivos. Além dis- 
so, o maior peso do dinheiro na política contemporânea parece condicionar de modo particular tanto a participação quanto a agenda (Jencks, 2002) ${ }^{6}$. De modo geral, a relação entre desigualdade socioeconômica e "apatia" política comparecem com alguma freqüência na literatura de ciência política e sociologia, especialmente a partir dos anos 80, e a avaliação geral é claramente negativa, sobretudo considerando o impacto da não-participação dos menos favorecidos sobre a legitimidade da democracia, em termos da supressão de agendas e perspectivas (Bennett, 1986; De Luca, 1995; Patterson, 2000). Finalmente, cabe notar que, mesmo quando a desigualdade política decorrente da desigualdade econômica pode ser mitigada por instituições políticas e legislação específica, como a lei de financiamento de campanhas, evidências recentes como a reforma da legislação americana apontam uma certa resiliência do sistema político como um todo a essa inovação (Oppel Jr., 2002).

Do ponto de vista dos direitos civis, trabalhos como os de O'Donnell (1999) e Santos (2001) chamam a atenção para uma importante deficiência no assim chamado "componente liberal" da democracia - a igualdade de direitos civis - em democracias recentes, ocasionada por desigualdades socioeconômicas extremas. O'Donnell argumenta que, mesmo tendo concluído de modo razoavelmente satisfatório a transição para regimes democráticos, e, portanto, alcançado progresso significativo do ponto de vista da extensão de direitos políticos, diversos países da América Latina têm falhado notavelmente na implementação de direitos civis iguais, pois a "lei" revela-se de fato uma para os poderosos locais, outra para os despossuídos. A evidência é farta, no acesso desigual a processos judiciais justos, em condições carcerárias desiguais, no tratamento desigual por parte das múltiplas burocracias públicas, em cargos públicos acumulados pelos mais favorecidos, afetando a intermediação de seus conflitos com os menos favorecidos, na repressão desigual a iniciativas de ação coletiva e no estigma de grupos sociais (Santos, 2001).

Parece lícito, pois, concluir que se as democracias reais representam a realização maior ou menor de ideais de igualdade de cidadania civil e política, esta realização é tanto mais remota, inter alia, quanto maior for o grau de desigualdade socioeconômica tolerado pelas sociedades. 


\section{DESIGUALDADE COMO CONSEQÜÊNCIA PREVISÍVEL E NÃO PREVISÍVEL}

Muitas das desigualdades socioeconômicas atuais se originaram de diferenciações, possivelmente associadas a características físicas, como sexo e idade, e habilidades ou inabilidades individuais indutivamente generalizadas a grupos étnicos, cujo propósito inicial era resolver problemas de coordenação e que, tendo extrapolado de modo não pretendido este intento, se incorporaram em práticas sociais, normas e instituições (Tilly, 1998; Barrington Moore Jr., 1999). Outras tantas se teriam estabelecido por meio de processos violentos de expropriação (como o cercamento de terras) e coerção (como a escravização), e se perpetuaram por meio de processos legais (Polanyi, 1980; Marx, 1970-71; Arendt, 1970). Algumas desigualdades vigentes, por exemplo, no mercado de trabalho premiariam diferenciadamente esforços, sacrifícios, apostas, escolhas, características individuais, expressando, ao fim e ao cabo, a variedade humana e as múltiplas liberdades de escolha por parte de produtores e consumidores (Hayek, 1993). Reparar todas essas desigualdades supõe duas coisas: em primeiro lugar, que todas elas devem ser reparadas; em segundo, que é possível modificar as tradições, o sistema legal e o mercado de modo a eliminá-las. A monstruosa engenharia social envolvida para obter, de todo modo, um resultado apenas duvidoso parece desaconselhar esta opção.

Alternativamente, tomarei como ponto de partida, no discernimento das desigualdades econômicas, entre as que devem ou não ser reparadas, a idéia de John Rawls (1971) de desigualdades injustas - as desigualdades socioeconômicas que tiveram sua origem em distribuição desigual de liberdades e oportunidades. Esta, aliás, me parece ser a linha demarcatória nas teorias normativas contemporâneas - a idéia razoavelmente tautológica de que as desigualdades que resultam das escolhas dos indivíduos são legítimas uma vez que estes tenham sido expostos a chances razoavelmente iguais de fazer aquelas escolhas. Colocada nestes termos, a questão é: como interpretar a noção de "chances iguais"?

A interpretação sugerida por Hayek é tomar chances iguais como conotando aleatoriedade ou impessoalidade, o domínio, por assim dizer, do princípio da indiferença. Nesse sentido, toda e qualquer desigualdade gerada pelo mercado (e amparada pela legalidade necessária ao seu funcionamento normal) é legítima, na medida em que o 
mercado é um mecanismo distributivo cego, indiferente à identidade dos agentes econômicos, e que liga os resultados dos indivíduos exclusivamente à utilidade dos seus talentos, habilidades e recursos para a sociedade (e não, por exemplo, a critérios hierárquicos ou discriminatórios). Diante da incerteza quanto aos resultados futuros (os valores específicos que a sociedade atribuirá aos bens que os indivíduos levam ao mercado), o mercado é o mecanismo que maximiza a igualdade de chances de sucesso dos indivíduos, na medida em que os produtores, dotados das informações fornecidas pelo sistema de preços (que os informa como a sociedade presentemente valoriza os resultados dos diferentes trabalhos e investimentos), são deixados livres para tomar suas decisões de produção. As desigualdades que, por ventura, resultam são, do ponto de vista dos agentes econômicos, razoavelmente imprevisíveis, aleatórias e, nesse sentido, "justas".

O que essa interpretação de igualdade de chances como liberdade econômica de escolha ignora é o problema da desigualdade de risco: 0 fato de que os produtores - os diversos grupos de trabalhadores e empresários - não enfrentam a incerteza quanto aos resultados futuros com o mesmo nível de vulnerabilidade, e que este é uma função, entre outras coisas, da riqueza à disposição desses indivíduos e grupos. Mas não apenas: pode-se acrescentar talentos e habilidades (mais ou menos dependentes do grupo social e do ambiente familiar em que os indivíduos estão inseridos), recursos sociais que podem ser mobilizados para diminuir essa vulnerabilidade ("capital social" e "capital coletivo"), recursos econômicos herdados, recursos cognitivos e simbólicos etc. Na verdade, Hayek, nos seus primeiros escritos de filosofia política, notadamente em The Road to Serfdom, mostra uma certa preocupação com a possibilidade de a desigualdade de riqueza afetar desigualmente as oportunidades de indivíduos e grupos, e revela uma certa ambigüidade quanto às implicações desse problema para a sua filosofia política. De um lado, há uma indicação forte da necessidade de planejar uma sociedade de mercado, em que os resultados econômicos são os máximos consistentes com uma noção de justiça não apenas como liberdade de escolha, mas também como liberdade de oportunidades (dentro, pode-se dizer, de uma agenda de pesquisa rawlsiana) (Hayek, 1979:102). Por outro, existe, já, a formulação de um argumento que se revelará vitorioso em sua filosofia política posterior: que a justiça distributiva conduz a dois resultados coletivamente muito ruins, tirania e ineficiência econômica. Porém, como en- 
sina Popper, justiça distributiva leva à tirania apenas se a alternativa democrática é descartada, ou ainda se "democracia" é entendida como a vontade da maioria, e não como um regime político onde a prestação de contas é máxima em comparação com as alternativas. Além disso, lembra Popper em famosa discordância com Hayek, também o poder econômico é coercitivo e requer controle, de modo que "liberdade" anseia por alguma forma de "justiça distributiva" (Popper, 1971; Kerstenetzky, 2002) ${ }^{7}$. Finalmente, a associação entre justiça distributiva e ineficiência depende de corroboração empírica, e a teoria econômica recente parece pender mais e mais para a associação simétrica entre justiça distributiva e eficiência econômica (cf. seção 2).

A tese rawlsiana (na verdade Rawls-Tilly), em contraste, interpreta "chances iguais" não apenas como liberdade de escolha, tal qual assegurada por mercados livres dentro dos marcos de um Estado de Direito, mas também como igualdade substantiva de oportunidades, a partir da observação de que a aleatoriedade hayekiana recobre uma certa regularidade nos processos de discriminação e exclusão. Nas sociedades em que prevalecem mercados livres, os indivíduos entram em transações econômicas conhecendo o fato de que suas chances de sucesso são substancialmente desiguais, e que os melhores preditores dessas chances são as posições que esses indivíduos ocupam nessas sociedades: classes, lugares de moradia, gênero, cor. As desigualdades são, do ponto de vista dos indivíduos e grupos, substancialmente previsíveis. Para restaurar a aleatoriedade hayekiana, e assim tornar as desigualdades justas, seria necessária a correção dessas desigualdades de oportunidades. Estas, de fato, interferem na efetivação das liberdades iguais dos indivíduos (não apenas econômicas, mas também civis e políticas) e nas chances de eles satisfazerem expectativas que são reconhecidas como legítimas nas sociedades modernas. Simplificadamente, essas chances de sucesso (C) são uma função direta $\mathrm{C}=\mathrm{f}(\mathrm{L}, \mathrm{O}, \mathrm{R})$, onde $\mathbf{L}$ são as liberdades, $\mathrm{O}$, as oportunidades, $\mathbf{R}$, renda e riqueza. Para impedir tradeoffs, como por exemplo a troca de liberdade por renda, Rawls estabelece uma ordenação lexicográfica ${ }^{8}$ dos argumentos da função, onde $\mathbf{L}>\mathbf{O}>\mathbf{R}^{9}$, e as seguintes regras de distribuição para cada um deles, que deveriam prevalecer em uma sociedade justa: $\mathbf{L}$ devem ser maximamente iguais (incluem, além do Estado de Direito, entre outros aspectos, legislação específica contendo os efeitos da concentração de riqueza sobre a igualdade de direitos políticos); $\mathbf{O}$ devem ser aproximadamente iguais, o que im- 
plica distribuição reparatória (essencialmente, oportunidades educacionais financiadas publicamente e restrições à concentração excessiva de riqueza e à herança que possam distorcer demasiadamente as oportunidades de realização); quanto à $\mathbf{R}$, a dispersão em sua distribuição deve trazer ganhos para todos (em particular para os menos favorecidos $)^{10}$. Na verdade, o chamado princípio da diferença, segundo o qual a desigualdade econômica se justificaria se viesse em benefício dos menos favorecidos, é o princípio da eficiência aplicado a uma distribuição de vantagens econômicas previamente ajustada por liberdades e oportunidades razoavelmente iguais: ele exclui todas as distribuições (corrigidas por igualdade de liberdades e aproximadamente de oportunidades) que não tragam vantagens para todos, em particular para os menos favorecidos ${ }^{11}$. Em contraste com o princípio da indiferença à Hayek, o princípio da diferença rawlsiano reconhece a desigualdade de risco ou de exposição ao risco, incorporando as retificações necessárias para que os indivíduos confrontem chances razoavelmente iguais ${ }^{12}$.

Em termos práticos, a justiça rawlsiana implicaria a consolidação do Estado de Direito, várias legislações restringindo os efeitos deletérios do poder econômico sobre direitos políticos, instituições clássicas do Estado de Bem-Estar Social, com especial ênfase na expansão das oportunidades educacionais financiadas pelo Estado, regulações várias para conter o poder de mercado de grandes empresas, restrições ao direito de herança e doações, garantia de um mínimo social etc ${ }^{13}$. A justiça rawlsiana acomodaria, pois, a eficiência econômica, a estabilidade social e a democracia em um referencial de justiça, o qual operaria como restrição aos arranjos econômicos eficientes e condição de possibilidade da estabilidade social e da democracia. Em particular, a justiça rawlsiana não requer nenhuma paideia específica que incida sobre, ou restrinja demasiadamente, as preferências dos indivíduos. As desigualdades injustas, que demandam retificação, são, ao fim e ao cabo, efeitos esperados de instituições injustas, ou insuficientemente justas, que inibem a importância das "escolhas individuais"14 na determinação dos resultados econômicos; trata-se, por conseguinte, de corrigir essas instituições usando como guia os princípios de justiça rawlsianos a partir de uma teoria de como essas desigualdades são geradas.

Mas, e se as desigualdades que emergem de sociedades corrigidas por instituições de justiça rawlsianas são, ou parecem ser, ainda mui- 
to grandes, colocando em risco, inclusive, objetivos razoavelmente consensuais, como coesão social, eficiência, democracia, que essas instituições buscavam também proteger? Nada a fazer? Segundo G. A. Cohen (1992), esse resultado indesejável apenas prova a inocuidade de uma noção de justiça que se baseia em instituições, em face da recalcitrância de um ethos ferozmente egoísta. Se o próprio ethos não for colocado em questão - as intenções e motivações dos indivíduos, as "preferências", por exemplo, dos executivos de grandes empresas por remunerações especialmente elevadas, como representadas na inelasticidade de suas funções de oferta de trabalho -, restringindo desta feita o domínio das preferências dos indivíduos, sua "liberdade de escolha" (algo a que Rawls não subscreveria), pouco se avançará em relação à inócua justiça rawlsiana em termos de redução das desigualdades. Segundo J. Cohen (2002), contudo, a justiça rawlsiana possui recursos para lidar com esse problema, sobretudo se assumirmos que também o ethos é, em última instância, afetado por instituições, em uma versão institucionalista forte da justiça rawlsiana: instituições justas devem influir tanto na oferta de qualificações (atenuando o poder de barganha dos detentores de altas remunerações) quanto nas disposições e atitudes dos indivíduos.

Em favor de Rawls (e contrariando G. A. Cohen) e sua ênfase nas instituições, pode-se argumentar que a capacidade de executivos (e trabalhadores qualificados de modo geral) para demandar e comandar incentivos (altas remunerações) depende não apenas de suas preferências como de condições objetivas dos mercados em que operam. Se a oferta de talentos e qualificações aumenta é razoável supor que aquela capacidade fica enfraquecida. E é aqui que a justiça institucional rawlsiana pode operar de modo bem-sucedido: estendendo a oferta de oportunidades educacionais de modo a ampliar a oferta de qualificações, e assim reduzir o poder de barganha dos bem qualificados. Entretanto, como casos recentes de corporações americanas têm evidenciado, a capacidade de executivos de grandes corporações $f a-$ zerem o mercado para suas qualificações, agindo, portanto, também sobre o lado da demanda pelo tipo de trabalho que oferecem, na medida em que, por exemplo, produzem a ilusão contábil de que seu talento é único, seu "produto" (alta rentabilidade das empresas que comandam, conforme reportam aos acionistas), diferenciado, faz com que ações exclusivamente do lado da oferta de qualificações se tornem relativamente inócuas (Krugman, 2002) (Quadro 4) ${ }^{15}$. A pergun- 
ta é: como democratizar esse tipo de oportunidade ou regular sua exploração? Pode bem acontecer (e as evidências são abundantes de que o processo já está em pleno curso) que o eventual poder de mercado dos agentes econômicos sirva de incentivo para inovações (como maquiagens contábeis, p. ex., o caso Enron, ou corrupção de objetivos de firmas de auditoria e análise de investimentos, como os casos recentes envolvendo a Arthur Andersen e a Merrill Lynch) de eficiência mais que duvidosa do velho ponto de vista da promoção de "vantagens para todos". Em que medida a regulação econômica é capaz de controlar o desvio de recursos para fins que aumentam as vantagens de alguns, mas que não trazem benefícios generalizados, e sim perdas - de empregos, de pensões, de ações, de capital físico -, é algo para o qual a evidência é ainda insuficiente. Parte substancial da regulação apóia-se em auditorias e estas parecem necessitar de auditagem também... De todo modo, democratizar a educação não parece ser a estratégia adequada para conter esse gênero de "desigualdades ineficientes".

\section{Quadro 4}

Evolução da Remuneração dos Executivos de

Corporações Americanas em relação à Remuneração

dos Trabalhadores Ordinários (Não-Supervisão)

\begin{tabular}{|c|c|}
\hline Ano & Razão das Remunerações \\
\hline 1980 & 45 \\
1995 & 160 \\
1997 & 305 \\
2000 & 458 \\
\hline
\end{tabular}

Fonte: Krugman (2002).

Ao lado das inovações ruins, como a maquiagem contábil e a corrupção de objetivos, há igualmente as boas inovações, de processos, produtos e organização, que aumentam a riqueza e que estão no core do capitalismo contemporâneo. Contudo, a mudança tecnológica também destrói empregos e capitais, como ensina um Schumpeter agora redivivo no core da teoria econômica (Baumol, 2002). E ainda que fortemente baseada em "qualificações" (a postulação de expansão das igualdades educacionais é, pois, progressista), torna-as rapidamente obsoletas, como a um grande número de empregos e capitais. O crescimento econômico baseado em mudança tecnológica rápida tem ocasionado, nos últimos quinze anos, maiores níveis de desigualdade 
econômica (Aghion et alii, 1998). A natureza dessas "desigualdades eficientes", causadas por inovações "boas" (que trazem crescimento), é algo que necessita exame. De um lado, os ganhos extras dos inovadores que viram oportunidade de ganhos onde ninguém mais viu (estavam no "lugar certo, na hora certa"); de outro, processos técnicos tornados prematuramente obsoletos, destruição de capital e empregos, perdas financeiras dos acionistas (que se encontravam no "lugar errado, na hora errada"). Parece claro que a expansão de oportunidades educacionais pouco pode fazer para restringir também esse tipo de desigualdade. Ao contrário, é em um ambiente onde a massa crítica de qualificações é atingida que é mais provável surgirem inovações (idem). Na medida em que os sistemas econômicos funcionam segundo o modelo de mudança técnica rápida, a equalização de oportunidades no sentido "antigo" vai ser sempre deficiente, cuidando no máximo do aspecto "hereditário" da desigualdade. O que certamente não é desprezível, mas a desigualdade interpessoal vai seguir sendo elevada e preocupante. A principal evidência desse fenômeno é a economia americana: a que possui tanto o maior nível de igualdade educacional entre as democracias ocidentais desenvolvidas quanto o maior nível de desigualdade econômica (Jencks, 2002; Devroye e Freeman, 2001).

Em síntese, o aumento em importância das desigualdades como conseqüência, agora imprevisível, da operação de instituições sociais e econômicas parece debilitar o potencial retificador das instituições. E uma vez que as desigualdades aumentam, são colocados em risco objetivos consensuais que estão no core de teorias da justiça como a de Rawls, tais como eficiência, estabilidade social e democracia. Como enfrentar essas dificuldades? Nas conclusões sugiro algumas alternativas, para reflexão futura.

\section{CONCLUSÕES}

Este exercício conclui com duas observações:

1) Um igualitarismo de tipo conseqüencialista é altamente recomendado se as desigualdades econômicas são percebidas como causando males sociais, políticos e econômicos. Neste caso, as desigualdades importam, e devem, sim, constituir objeto de preocupação das políticas públicas, na medida em que afetam objetivos "consensuais" ou não distributivos, como redução da pobreza, eficiência econômica, 
coesão social e democracia. É, pois, politicamente realista enfrentá-las. Argumentos e evidências parecem particularmente fortes para os objetivos econômicos e persuasivos para os problemas de coesão social e baixa qualidade da democracia.

2) Se as desigualdades incomodam porque são injustas, há uma certa indeterminação a ser resolvida. E aqui parece relevante refletir sobre as desigualdades não tanto como causa de males, mas como conseqüência de processos e procedimentos. As desigualdades podem ser pensadas tanto como conseqüência principalmente previsível de instituições injustas (mundo $A$ ), quanto principalmente imprevisível (perversa, não-pretendida) de instituições justas (mundo $B$ ). Em termos da justiça rawlsiana, stricto sensu, o mundo $B$ não é injusto. Entretanto, se as desigualdades resultantes do mundo $B$ são ainda muito grandes, podem comprometer coisas que também têm valor, e valor maior, para a justiça rawlsiana, como estabilidade social, democracia e eficiência. Rawls espera, portanto, creio eu, estar operando no mundo $A$, no qual seus princípios de justiça institucional devem ser efetivos. A decisão quanto ao estilo de igualitarismo deverá, pois, depender de qual dos mundos possíveis, $A$ ou $B$, irá prevalecer. Enquanto o mundo $A$ aconselha a justiça rawlsiana, o mundo $B$ recomenda pelo menos duas opções: ou algo na linha da alternativa libertária de Phillipe van Parijs com institucionalidade mínima (o mercado cuida da geração de riqueza, o Estado, da redistribuição, sobretudo na forma da instituição de uma renda universal básica, a maior possível), ou ainda uma justiça rawlsiana (com típica ênfase na educação) modificada por intenso monitoramento direto das desigualdades (via taxação sobre renda e riqueza), de modo a garantir que os objetivos consensuais também embutidos na justiça rawlsiana não sejam danificados pelas desigualdades, agora, justas.

(Recebido para publicação em outubro de 2002) 


\section{NOTAS}

1. Considerando-se a razão entre a renda média dos $10 \%$ mais ricos e a dos $40 \%$ mais pobres, a posição do Brasil é a pior do mundo conhecido (Barros et alii, 2000a). Além disso, enquanto o coeficiente de Gini brasileiro é de cerca de 0,60 , o do mundo como um todo, incluídos os miseráveis da África subsaariana e os super-ricos da nova economia, é de cerca de 0,66 (Milanovic, 1999 apud Therborn, 2001).

2. Sigo aqui uma boa tradição da teoria da escolha social, que se inicia com o trabalho pioneiro de Kenneth Arrow (1963 [1951]), para a qual, em sua ordenação de preferências entre estados sociais alternativos, indivíduos racionais consultam não apenas seu estômago, mas também seus valores.

3. Para problemas desse gênero, ver Shapiro (2002). Não há evidência clara, p. ex., de que os menos favorecidos apóiem políticas redistributivas. Há várias razões para isso, sobretudo de natureza cognitiva (cf. idem). Por outro lado, o ethos social pode desempenhar um papel importante na disposição maior ou menor dos mais favorecidos em sustentar políticas redistributivas. Um argumento que liga o auto-interesse dos mais favorecidos ao destino dos menos favorecidos é o que enfatiza o problema da deterioração ambiental (externalidades negativas associadas à desigualdade, como saúde pública, violência, degradação do meio ambiente, degradação cultural) (Patterson, 2002). Mas, o grau em que esses efeitos apelam ao interesse próprio dos mais favorecidos depende da capacidade de estes privatizarem os bens públicos: condomínios fechados, carros blindados, TVs a cabo, subtração de sua presença do espaço urbano comum etc.

4. Um terceiro argumento referido por Aghion et alii (1998:23-28) é a associação direta entre desigualdade extrema de riqueza e volatilidade macroeconômica. Comparar com argumentos que propõem uma ligação indireta, através da instabilidade institucional e política (cf. Alesina e Perotti, 1996).

5. Coesão social, trivialmente, por oposição à segmentação ou ruptura social violenta. A idéia é que, em sociedades onde não seja pervasiva a crença na igualdade moral entre os indivíduos, como, por exemplo, nas sociedades de castas, a existência das desigualdades duráveis, no sentido de Tilly, não deveria ser especialmente problemática do ponto de vista da coesão social, como o é em sociedades onde aquela crença é nutrida.

6. Mesmo em termos de participação eleitoral, o aumento da desigualdade nos EUA, ao longo dos anos 80, coincide com o declínio da participação eleitoral dos menos afluentes e a subseqüente inércia do sistema político em relação à desigualdade (Jencks, 2002).

7. Para uma comparação entre Hayek e Popper a respeito da esfera legítima de intervenção do governo, ver Kerstenetzky (2002). Ver, também, Popper (1971, esp. cap. 7, vol. I: The legal and the social system). Neste capítulo, encontra-se também a (menos famosa) concordância entre Popper e Marx quanto à distinção entre liberdade formal e liberdade real ou substantiva.

8. Isto é, análoga à ordenação alfabética das palavras em um dicionário.

9. O símbolo " >" indica prioridade absoluta. 
10. "First Principle: Each person is to have an equal right to the most extensive total system of equal basic liberties compatible with a similar system of liberty for all. [...] Second Principle: Social and economic inequality are to be arranged so that they are both: (a) to the greatest benefit of the least advantaged, consistent with the just savings principle [the difference principle], and (b) attached to offices and positions open to all under fair equality of opportunity." (Rawls, 1999)

11. A interpretação do princípio da diferença que aqui proponho encontra apoio, sobretudo, na afirmação de Rawls de que este selecionaria o ponto de maior eficiência na curva de contribuição (cf. Rawls, 2001:68; ver, também, idem:52).

12. O princípio da diferença destina-se a regular as desigualdades econômicas residuais, permitindo apenas aquelas que tragam vantagens para ricos e "pobres", e reconhecendo: (1) a incompletude da igualdade de oportunidades; (2) que as diferenças individuais (talentos, habilidades, ambiente familiar) podem gerar importantes desigualdades socioeconômicas; (3) o efeito imponderável da sorte.

13. Em Justice as Fairness: A Restatement, Rawls distingue o Estado de Bem-Estar Social do ideal que endossa, seguindo James Meade: a democracia de proprietários (property-owning democracy). Em suas palavras: "the background institutions of property owning democracy work to disperse the ownership of wealth and capital, and thus to prevent a small part of society from controlling the economy, and indirectly, political life as well. By contrast, welfare-state capitalism permits a small class to have a near monopoly of the means of production. Property owning democracy avoids this, not by the redistribution of income to those with less at the end of each period, so to speak, but rather by ensuring the widespread ownership of productive assets and human capital (that is, education and trained skills) at the beginning of each period, all this against a background of fair equality of opportunity." (2001:139)

14. Rawls não restringe significativamente o domínio das "preferências" dos indivíduos, em termos dos diferentes estilos de vida que eles desejam realizar. Mais adiante, no presente artigo, restrições à escolha, no sentido acima, aparecem embutidas na crítica de G. A. Cohen a Rawls. Na penúltima seção, a própria relevância da dimensão de escolha individual é questionada, em uma abordagem menos determinista dos resultados socioeconômicos dos indivíduos. Mas a dimensão de não-liberdade de escolhas significativas é tratada apropriadamente por Rawls, na medida em que ele reconhece a influência de liberdades e oportunidades, em sentido amplo, sobre o alcance das escolhas.

15. Ver Krugman (2002) para o aumento das desigualdades salariais nos Estados Unidos, estando estas relacionadas com o poder de mercado dos executivos e a cultura da maximização do valor das ações. 


\section{REFERÊNCIAS BIBLIOGRÁFICAS}

AGHION, P., GARCÍA-PEÑALOSA, C. e CAROLI, E. (1998), “Inequality and Economic Growth", in P. Aghion e J. Williamson (eds.), Growth, Inequality and Globalization. Cambridge, Cambridge University Press.

ALESINA, A. e PEROTTI, R. (1996), “Income Distribution, Political Instability, and Investment". European Economic Review, vol. 40, pp. 1203-1228.

ARENDT, H. (1970), On Violence. New York, Harcourt \& Brace.

ARROW, K. (1963) [1951], Social Choice and Individual Values. New York, John Wiley \& Sons, Inc.

BARRINGTON MOORE JR. (1999), "Princípios da Desigualdade Social", in Aspectos Morais do Crescimento Econômico e outros Ensaios. Rio de Janeiro/São Paulo, Record.

BARROS, R. P., HENRIQUES, R. e MENDONÇA, R. (2000a), “Estabilidade Inaceitável: Desigualdade e Pobreza no Brasil", in R. Henriques (org.), Desigualdade e Pobreza no Brasil. Rio de Janeiro, IPEA.

. (2000b), "Education and Equitable Economic Development". Economia, vol. 1, no 1 .

BARROS, R. P., MENDONÇA, R., DELIBERALLI, P. e LOPES, C. (2000c), “Impactos da Distribuição sobre a Eficiência Agrícola e a Pobreza no Nordeste", in R. Henriques (org.), Desigualdade e Pobreza no Brasil. Rio de Janeiro, IPEA.

BAUMOL, W. (2002), Free Market Innovation Machine: Analyzing the Growth Miracle of Capitalism. Princeton, Princeton University Press.

BENABOU, R. (1996), “Inequality and Growth”, in B. Bernanke e J. Rotemberg (eds.), NBER Macroeconomics Annual. Cambridge, MA, MIT Press.

BENNETT, S. E. (1986), Apathy in America - 1960/1984 - Causes and Consequences of Citizen Political Indifference. New York, Transnational Publishers, Inc.

BIRDSALL, N. e LONDONO, J. L. (1997), “Asset Inequality Matters: An Assessment of the World Bank's Approach to Poverty Reduction". American Economic Review, vol. 82, n 2 (AEA Papers and Proceedings), pp. 32-37.

COHEN, G. A. (1992), "Incentives, Inequality, and Community", in G. B. Patterson (ed.), Tanner Lectures on Human Values (vol.13). Salt Lake City, University of Utah Press.

. (1995), “The Pareto Argument for Inequality". Social Philosophy and Policy, vol. 12, pp. 160-185.

. (1997), "Where the Action Is: On the Site of Distributive Justice". Philosophy and Public Affairs, vol. 26, pp. 3-30.

COHEN, J. (2002), Taking People as they Are? Manuscrito.

DAHL, R. (1996), “Equality versus Inequality”. PS: Political Science and Politics, vol. 29, no -4 .

DEININGER, K. e SQUIRE, L. (1998), “New Ways of Looking at Old Issues”. Journal of Development Economics, vol. 57, pp. 259-287. 
DE LUCA, T. (1995), The Two Faces of Political Apathy. Philadelphia, Temple University Press.

DEVROYE, D. e FREEMAN, R. (2001), “Does Inequality in Skills Explain Inequality in Earnings across Advanced Countries?". Cambridge, National Bureau of Economic Research, fevereiro.

EPSTEIN, R. (2002), “Against Redress”. Daedalus, winter.

ESTLUNG, D. (1998), “Liberalism, Equality, and Fraternity in Cohen's Critique of Rawls". The Journal of Political Philosophy, vol. 6, nํ1, pp. 99-112.

FERREIRA, F. H. G. (1999), "Inequality and Economic Performance - A Brief Overview to Theories of Growth and Distribution". http://www.worldbank.org/poverty/inequal/index.htm.

_. (2000), “Os Determinantes da Desigualdade de Renda no Brasil: Luta de Classes ou Heterogeneidade Educacional?", in R. Henriques (org.), Desigualdade e Pobreza no Brasil. Rio de Janeiro, IPEA

_ e LITCHFIELD, J. A. (2000), “Desigualdade, Pobreza e Bem-Estar Social no Brasil”, in R. Henriques (org.), Desigualdade e Pobreza no Brasil. Rio de Janeiro, IPEA.

GALBRAITH, J. (2002), “A Perfect Crime: Global Inequality”. Daedalus, winter.

GUANZIROLI, C. (1999), "Reforma Agrária e Globalização da Economia: O Caso do Brasil". Econômica, vol. 1, nํำ.

HAYEK, F. A. (1979), The Road to Serfdom. London/Henley, Routledge \& Kegan.

_. (1993), The Constitution of Liberty. London, Routledge \& Kegan Paul.

JENCKS, C. (2002), “Does Inequality Matter?”. Daedalus, winter.

KERSTENETZKY, C. L. (1999), “Desigualdades Justas e Igualdade Complexa”. Lua Nova, $\mathrm{n} \times 47$.

. (2000), "Progresso e Pobreza na Economia Política Clássica”. Anais do XXVIII Encontro Nacional da ANPEC. Campinas, SP, ANPEC.

_. (2002), Human Action, Not Human Design? Cambridge, MA. Manuscrito.

KRUGMAN, P. (2002), “Enemies of Reform”. New York Times (editorial), 21 de maio.

LIJPHART, A. (1999), Patterns of Democracy: Government Forms and Performance in Thirty Six Countries. New Haven, Yale University Press.

MARX, K. (1970-71), A Origem do Capital: A Acumulação Primitiva. São Paulo, Global.

NEUBOURG, C. de. (2002), The Welfare Pentagon, Shifts in Poverty and Inequality and Studying Vulnerability. Workhop Transforming the Democratic Balance among the State and Society. Minda de Gunzburg Center for European Studies / Harvard University. Manuscrito.

O'DONNELL, G. (1999), "Polyarchies and the (Un)Rule of Law in Latin America", in G. O'Donnell, J. Méndez e P. S. Pinheiro (eds.), The (Un)Rule of Law and the Underprivileged in Latin America. Notre Dame, IN, University of Notre Dame Press.

OPPEL JR., R. A. (2002), “Soft Money Goes into Effect, but the Effect Is Uncertain”. New York Times (editorial), 23 de junho. 


\section{Celia Lessa Kerstenetzky}

PATTERSON, P. (2000), “Nonvirtue Is Not Apathy - Warrants for Discourse and Citizen Dissent". American Review of Public Administration, vol. 30, no 3.

_. (2002), "Beyond Compassion". Daedalus, winter.

POGGE, T. (2000), “On the Site of Distributive Justice: Reflections on Cohen and Murphy". Philosophy and Public Affairs, vol. 29, no 2 .

POLANYI, K. (1980), A Grande Transformação. Rio de Janeiro, Campus.

POPPER, K. (1971), The Open Society and its Enemies. Princeton, Princeton University Press.

RAE, D. (1999), "Democratic Liberty and Tyrannies of Place", in I. Shapiro e C. Hacker-Cordón (eds.), Democracy's Edges. New York, Cambridge University Press.

RAWLS, J. (1999) [1971], A Theory of Justice. Cambridge, MA, The Belknap Press of Harvard University Press.

. (2001), Justice as Fairness: A Restatement. Cambridge, MA, The Belknap Press of Harvard University Press.

SANTOS, W. G. dos. (2001), A Democracia e seu Futuro no Brasil. Rio de Janeiro. Manuscrito.

SHAPIRO, I. (2002), "Why the Poor don't Soak the Rich". Daedalus, winter.

SMITH, A. (1983) [1776], A Riqueza das Nações. São Paulo, Abril Cultural.

THERBORN, G. (2001), Globalization and Inequality: Issues of Conceptualization and of Explanation. Rio de Janeiro. Manuscrito.

TILLY, C. (1998), Durable Inequality. Berkeley, University of California Press.

VAN PARIJS, P. (1995), Real Freedom for All. Oxford, Clarendon Press. . (2001), What's Wrong with a Free Lunch? Boston, Beacon Press.

WILliAMS, A. (1998), "Incentives, Inequality, and Publicity". Philosophy and Public Affairs, vol. 27, nㅇ 3, pp. 225-247. 


\section{ABSTRACT}

\section{Why Worry about Inequality}

This article presents arguments from various fields to contend that socioeconomic inequalities be given priority treatment by national public policies, especially in countries where such inequalities abound. Based on the economic, sociological, and political science literature, the article gathers hypotheses and evidence indicating that inequalities, especially when excessive, should concern all those (even non-egalitarians), who ascribe importance to such objectives as economic growth, poverty reduction, social cohesion, and democracy. In addition, based on a reading of normative perspectives, the article attempts to map some of the challenges currently faced by egalitarianism. It concludes that even under pressure, especially from certain inherent aspects of contemporary economic inequalities, egalitarianism can develop in several directions.

Key words: socioeconomic inequalities; egalitarianism; theories of justice; equality of opportunities

\section{RÉSUMÉ}

\section{Pourquoi se Préoccuper des Inégalités}

Dans cet article, on réunit des arguments issus de disciplines diverses plaidant pour l'examen prioritaire par les politiques nationales des inégalités socioéconomiques, surtout dans les pays où elles sont très accentuées. Dans la littérature économique, sociologique et de science politique, on relève des hypothèses et des justifications montrant que les inégalités, particulièrement quand elles sont excessives, doivent être l'un des soucis de tous ceux qui, et y compris des non égalitaires, accordent une importance à des objectifs tels que la croissance économique, la réduction de la pauvreté, la cohésion sociale et la démocratie. Par ailleurs, à partir de certaines perspectives normatives, on cherche à situer quelques-uns des enjeux auxquels se heurte l'égalitarisme actuellement. Pour conclure, on affirme que, malgré des contraintes liées à certains aspects des inégalités économiques contemporaines, l'égalitarisme dispose de quelques directions où se développer.

Mots-clé: inégalités socioéconomiques; égalitarisme; théories de la justice; égalité de chances 